\title{
Antibiotic use in poultry production; a cross-sectional study in a selected district in Sri Lanka
}

\author{
Ubeysekara HA ${ }^{1}$, Ranaweera NPNM ${ }^{2}$, Peiris $\mathrm{HH}^{2}$, Wijayaratne WMDGB ${ }^{3}$ \\ ${ }^{I}$ Provincial Director of Health Services Office - Southern Province, Ministry of Health, Sri Lanka. \\ ${ }^{2}$ Department of Medical Laboratory Science, Faculty of Allied Health Sciences, University of Ruhuna, Sri Lanka. \\ ${ }^{3}$ Department of Microbiology, Faculty of Medicine, University of Ruhuna, Sri Lanka.
}

Correspondence: $\quad$ Dr. W. M. D. Gaya Bandara Wijayaratne

e-mail: gayabw@yahoo.co.uk

D https://orcid.org/0000-0002-8330-3597

Submitted on 08.06.2021 and accepted for publication on 28.06 .2021

\begin{abstract}
Introduction: Rampant use of antibiotics in animal husbandry contributes significantly to the development and spread of antibiotic resistance. This study determines the antibiotic activity in poultry feed and assesses the knowledge on feeding practices and their potential effects on antimicrobial resistance among poultry farm owners.
\end{abstract}

Methods: Poultry feed available for sale in shops and ready to serve poultry feed and water samples from selected farms in Kegalle District, Sri Lanka were tested for the antibiotic activity using the agar well diffusion method against three control organisms; Staphylococcus aureus ATCC25923, Escherichia coli ATCC25922 and Pseudomonas aeruginosa ATCC27853 and the zone of inhibition around each well was measured. All farm owners were interviewed and basic details regarding the farm such as area, number of animals, water source and the awareness of farm owners regarding antibiotic use in poultry feeds and water source were obtained.

Results: No antibiotic activity was detected in commercially available poultry feed in selected shops (5/5) and ready to serve poultry feed in selected farms (18/18). An antibacterial effect was detected in water samples collected from $33.33 \%(6 / 18)$ of farms. Seventy-eight percent (14/18) of farm owners declared that they administer different types of additives containing antibiotics along with drinking water served to animals. Forty-four percent of farm owners believe that usage of antibiotics in poultry is not a good practice and harmful for human health while a similar percentage claim that it is a favorable practice as it benefits them economically. None of the farm owners were aware that the use of antibiotics in poultry can contribute to the increasing antibiotic resistance in the community.

Conclusion: Commercially available poultry feeds in shops and ready to serve poultry feeds in farms did not demonstrate any antibiotic activity. However, antibiotic activity was detected in drinking water served to animals due to incorporation of antibiotic containing additives beyond the prevailing guidelines. The awareness of farm owners on antibiotic use in poultry and its effects on the increase of antibiotic resistance in the community is unsatisfactory.

Key words: Antimicrobial resistance, antibiotic activity, food additives, poultry feed. 


\section{Introduction}

Poultry is the main livestock species in food production in the world as well as in Sri Lanka. Use of antibiotics as feed additive has become one of the key practices in modern poultry production as it supports growth promotion in animals and helps to treat and prevent infections in poultry. However, it contributes to the development of antibiotic resistance in both animals and humans.

More than $60 \%$ of all antibiotics produced worldwide are employed during animal production for both therapeutic and non-therapeutic purposes (1). In the United States, approximately $80 \%$ of total antibiotics consumed are used in the livestock sector (2). According to the US Food and Drug Administration, 6.1 million kilograms of medically important antibiotics were sold to US animal producers in 2019, of which 3\% was being used for chicken (3).

Furthermore, a considerable portion of the administered antibiotic (17\%-90\%) is passed to the environment as the original compound or its toxic metabolites directly through urine and faeces. The remnants of poultry feed also contribute to environmental contamination. The emergence of antibiotic resistance genes has been reported around the world due to the misuse of these drugs in animal production (4). The antimicrobial usage in animal husbandry is projected to increase by $67 \%$, and that of poultry by $129 \%$ by $2030(5)$.

In Europe, salmonella bacteria from poultry and swine showed resistance levels reaching over 80 percent to tetracyclines, sulfonamides and ampicillin. Such data in most of the world are sparse. A study done in the Kandy district, Sri Lanka has identified some bacteria, resistant towards the tetracyclines and enrofloxacin in poultry litter and agricultural soils (6).

The World Health Organization (WHO) has called all nations to develop national strategies to minimize this serious threat of antimicrobial resistance. They have recommended to have an overall reduction in the use of all classes of medically important antimicrobials in food animals and a complete restriction of the use of antibiotics for growth promotion and for the prevention of infectious diseases. Furthermore, WHO suggests that antimicrobial agents that are categorized as critically significant for humans should not be used to treat or control clinically diagnosed infections in farm animals (7). Sweden is known to be the first country in the world to ban the use of antimicrobial agents for growth promotion in 1986 and prophylaxis in 1988 (1). In 2017, FDA banned the use of antibiotics as growth promoters (8). At present, the only recommended growth promoters that can be used in Sri Lankan poultry industry are Avoparcin, Carbadox, and Flavophospholipol (9).

The Ministry of Health in Sri Lanka has formulated "A national strategic plan for combating antimicrobial resistance in Sri Lanka 2017 - 2022" to support global efforts to address antimicrobial resistance. Specific objective 4.3 under the $4^{\text {th }}$ strategy of this will ensure the prudent use of antimicrobial agents in animals and in agriculture. Although provisions under Animal Disease Act (No. 59 of 1992) and Animal Feed Act (15 of 1986) are currently available to regulate the importation, manufacturing and distribution of antimicrobials in the veterinary sector; several gaps have been identified to fulfil the regulatory mechanism that needs to ensure the prudent use. The implementation of existing regulation is hampered due to limited resources. It is planned to establish a monitoring and evaluation system to ensure rational use of antimicrobials in animal husbandry. (10)

Therefore, the emergence of antibiotic resistance is a global challenge in which antibiotic usage in animal husbandry plays an important role. Data on antibiotic consumption in livestock is limited worldwide. Poultry farms occupy a dominant place in the livestock sector in Sri Lanka due to high consumption of chicken meat and eggs. As a result, poultry farms in Sri Lanka may be contributing vastly for the development of antimicrobial resistance both in human and animals. This study was designed to determine the antibiotic activity in poultry feeds and drinking water for animals used in poultry production in a selected district in Sri Lanka.

\section{Methods}

A community-based descriptive cross-sectional study was carried out in poultry farms and poultry feed shops in Kegalle District, Sri Lanka in 2019. 


\section{Determining the antibiotic activity in poultry feed available in shops}

Two samples from two different types of poultry feed available for sale from five randomly selected shops in Kegalle District were collected into commercially available single-use sterile containers. Samples were stored at $2-8^{\circ} \mathrm{C}$ in the refrigerator and were transported to the microbiology laboratory in the same condition in cold boxes as soon as possible to determine the antibiotic activity using agar well diffusion method.

Mueller Hinton agar plates were inoculated with a suspension equivalent to MacFarland 0.5 turbidity standard prepared from each control organism; Staphylococcus aureus ATCC25923, Escherichia coli ATCC25922 and Pseudomonas aeruginosa ATCC27853. Five grams (5 g) of each food sample was mixed with $25 \mathrm{ml}$ of sterile distilled water using a vortex mixture. Fifty microlitre $(50 \mu \mathrm{l})$ each from the suspensions of food samples from one shop (in triplicate), positive control (gentamicin), and negative control (sterile distilled water) were placed in each well with a diameter of $6 \mathrm{~mm}$. All plates were incubated at $35^{\circ} \mathrm{C}, 18-24$ hours and the zone of inhibition around each well was measured in millimeters.

\section{Determining the antibiotic activity of ready to serve poultry feed and water which are in poultry farms}

Eighteen poultry farms were selected from the Kegalle District based on the sample size calculation using the formula for the descriptive study (11) and the prevalence of antibiotic resistance in poultry feed used in poultry production in Galle taken as $25 \%(12)$.

Farm owners of all eighteen farms were interviewed by the principal investigator to obtain details such as the area of the farm, number of animals, feeding frequency and amount, water source, using additives containing antibiotics to water and poultry feed, and awareness of farm owners regarding antibiotic use in poultry.

Three samples of poultry feed and three water samples that are ready to serve were collected from different places of each farm. A sample from each available additive used along with food or water was obtained. Sample collection, temporary storage, transport and testing follow the same procedure mentioned under testing of poultry feed from shops.

Five grams ( $5 \mathrm{~g}$ ) of each food sample was mixed with $25 \mathrm{ml}$ of sterile distilled water using a vortex mixture to prepare a suspension. From a collected water sample, $20 \mathrm{ml}$ was centrifuged to separate the last $5 \mathrm{ml}$ of the deposit. When the additives were available, the analysis was done from the neat sample (original concentrations) and at diluted concentrations used to feed poultry. All these samples were tested in triplicate for antibiotic activity using the agar well diffusion method.

Ethical approval was obtained from the Ethics Review Committee of the Faculty of Allied Health Sciences, University of Ruhuna, Galle and permission was obtained from the local authority.

\section{Results}

Antibiotic activity of poultry feed available in shops

Two types of poultry feed were available at the five selected shops in Kegalle District, one for chicks and the other for adult animals. All the tested samples did not show any antibiotic activity by the test performed against three standard organisms.

\section{Antibiotic activity of ready to serve poultry feed in poultry farms}

Only chickens were raised in all the selected 18 farms. The size of the farm varies from $100-1500 \mathrm{~m}^{2}$ (mean $672 \mathrm{~m}^{2}$ (SD 362.7), median $750 \mathrm{~m}^{2}$ ) and the number of animals in the herd ranged from 100 3500 (mean 1422 (SD 1133.6), median 1100). Commercially available food is being used to feed the poultry and it is served approximately $10 \mathrm{~g}$ of poultry feeds per animal, two times a day. All samples of poultry feed that are ready to serve did not show any antibiotic activity by the tests performed against three standard organisms. 
Determining the antibiotic activity of ready to serve water in poultry farms

In most of the farms $(14 / 18,78 \%)$ well water is being used as the water source and the rest use pipe born water from the water supply board. Same proportion of farms $(14 / 18,78 \%)$ declare that they incorporate one or more additives to the water being served to animals. Of the farms where additives are added to drinking water, antibacterial activity was detected in water samples collected from 6 farms $(6 / 14$, 42.9\%). Among these, water samples from 5 farms show anti-staphylococcal activity (Figure 1), 3 farms show anti-E. coli activity (Figure 2) and 2 farms show antipseudomonal activity (Figure 3 ).
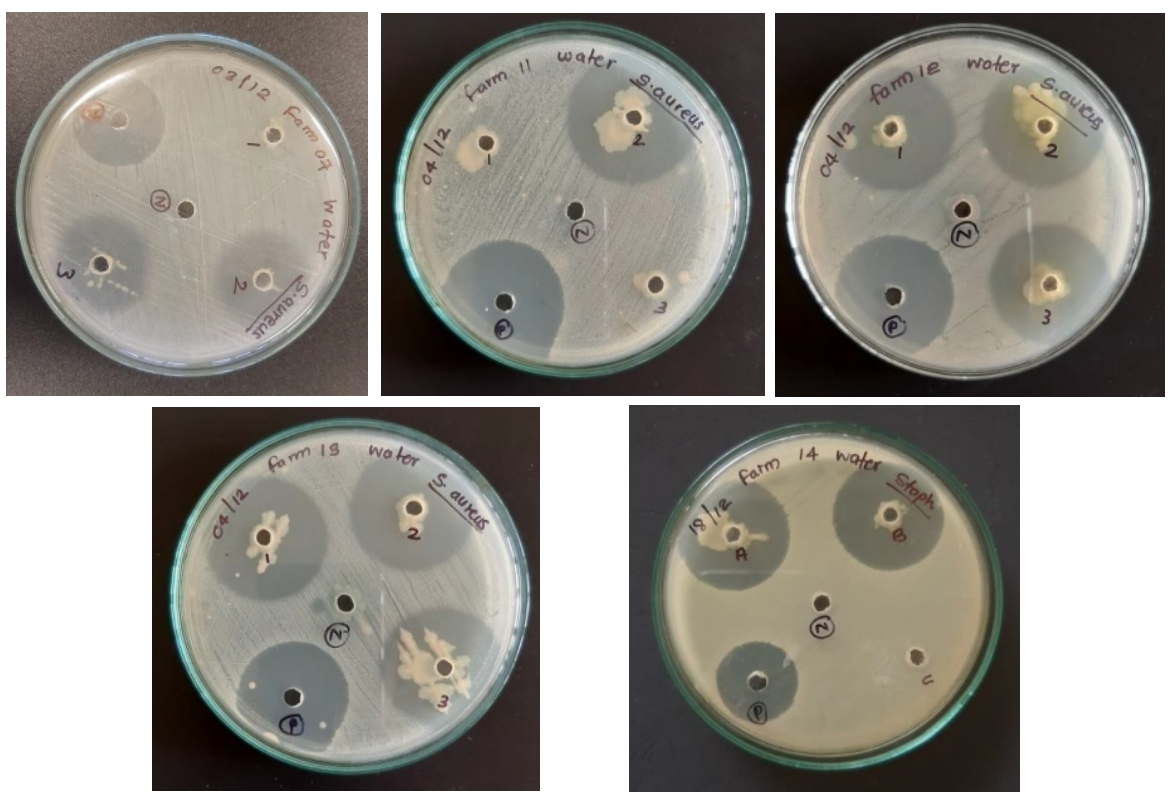

Figure 1: Antibiotic activity of water samples collected from farm No. 7, 11, 12, 13 and 14 against Staphylococcus aureus ATCC25923
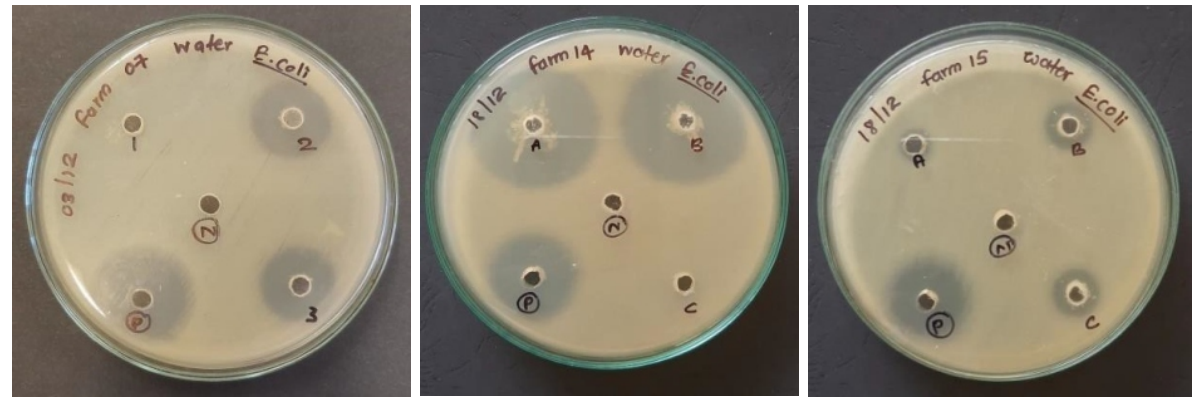

Figure 2: Antibiotic activity of water samples collected from farm No. 7, 14 and 15 against Escherichia coli ATCC25922
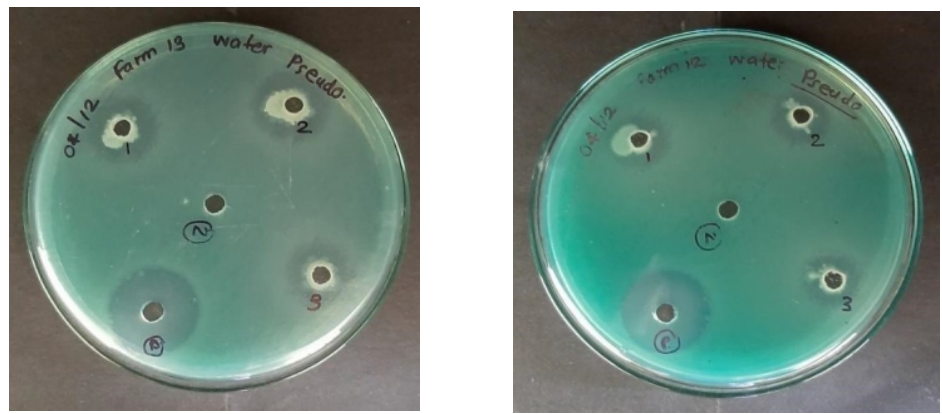

Figure 3: Antibiotic activity of water samples collected from farm No. 12 \& 13 against Pseudomonas aeruginosa ATCC27853 


\section{Antibiotic activity of additives used along with water}

The study has identified 8 different types of additives used by the farm owners that were incorporated into water to be served to the poultry (Table 1$)$. Two of the additives (2/8) did not show any antibacterial activity. Rest of the samples (6/8) demonstrated antibacterial activity in the ready to serve concentrations of the additive used to incorporate into water served to poultry (Table 2). Out of them, comparatively higher antibiotic activity than the positive control was demonstrated by the additive number 2, 5, 6 and 7 against Staphylococcus aureus ATCC25923 and by the additive number 2, 5 and 7 against Escherichia coli ATCC25922.

Neat concentrations of only 4 additives were produced by farm owners, of which 3 has demonstrated antibacterial activity to the neat concentration. Among them the zone of inhibition detected in additives number 1 and 4 were more or less equal to the positive control indicating an equal antibiotic activity as the positive control. But zones of inhibition detected in additive number 2 was more than two times that of the positive control indicating higher antibiotic activity.

Table 1: Description of additives used to incorporate into water served to poultry

\begin{tabular}{|c|c|c|}
\hline $\begin{array}{l}\text { Additive } \\
\text { number }\end{array}$ & Content & Remarks \\
\hline 1 & $\begin{array}{l}\text { A liquid complementary feed } \\
\text { composed of carbonic acids and } \\
\text { secondary plant compounds that } \\
\text { shows some antibiotic effect }\end{array}$ & $\begin{array}{l}\text { Used to improve the feed intake and the body } \\
\text { weight gain (a growth promoter). Destroy } \\
\text { bacterial pathogens in gastrointestinal tract. }\end{array}$ \\
\hline 2 & $\begin{array}{l}100 \mathrm{mg} \text { of Enrofloxacin (a synthetic } \\
\text { fluoroquinolone antimicrobial agent) } \\
\text { per } 1 \mathrm{ml}\end{array}$ & $\begin{array}{l}\text { Used to treat Colibacillosis, Salmonellosis } \\
\text { and infections caused by Mycoplasma } \\
\text { species. }\end{array}$ \\
\hline 3 & Not declared & $\begin{array}{l}\text { Used to increase the body weight and to } \\
\text { protect the farm from bacterial infections. } \\
\text { Controls the bad odour of cages when } \\
\text { sprayed on the cage floor. }\end{array}$ \\
\hline 4 & $\begin{array}{l}100 \mathrm{mg} \text { of Vitamin } \mathrm{E} \text { and } 0.5 \mathrm{mg} \text { of } \\
\text { Selenium per } 1 \mathrm{ml}\end{array}$ & $\begin{array}{l}\text { Used to fight muscular dystrophy, build a } \\
\text { better immune system and enhance egg } \\
\text { production. }\end{array}$ \\
\hline 5 & $\begin{array}{l}200 \mathrm{~g} \text { of Sulfamethazine and } 40 \mathrm{~g} \text { of } \\
\text { Trimethoprim per } 1 \mathrm{~kg}\end{array}$ & $\begin{array}{l}\text { An antibiotic used to treat infections caused } \\
\text { by Gram positive and Gram negative bacteria } \\
\text { including E. coli, Salmonella and Pasteurella. }\end{array}$ \\
\hline 6 & $\begin{array}{l}\text { Tylosin }(100 \% \mathrm{w} / \mathrm{w}) \text { (a macrolide } \\
\text { antibiotic) }\end{array}$ & $\begin{array}{l}\text { Treatment of chronic respiratory diseases } \\
\text { and necrotic enteritis caused by Mycoplasma } \\
\text { species and Clostridium perfringens } \\
\text { respectively. }\end{array}$ \\
\hline 7 & Neomycin and Oxytetracycline & $\begin{array}{l}\text { Used to control gastrointestinal and } \\
\text { Mycoplasma infections. }\end{array}$ \\
\hline 8 & Not declared & Use not declared \\
\hline
\end{tabular}


Table 2: Zones of inhibition measured in millimeters against three standard organisms against the neat concentration and the ready to serve concentration of additives

\begin{tabular}{|c|c|c|c|c|c|c|}
\hline \multirow{2}{*}{$\begin{array}{l}\text { Additive } \\
\text { number }\end{array}$} & \multicolumn{2}{|c|}{ S. aureus } & \multicolumn{2}{|l|}{ E. coli } & \multicolumn{2}{|c|}{ P. aeruginosa } \\
\hline & Neat & $\begin{array}{c}\text { Ready to } \\
\text { serve }\end{array}$ & Neat & $\begin{array}{c}\text { Ready to } \\
\text { serve }\end{array}$ & Neat & $\begin{array}{c}\text { Ready to } \\
\text { serve }\end{array}$ \\
\hline 01 & 29 & 0 & 25 & 0 & 23 & 0 \\
\hline 02 & 46 & 33 & 54 & 38 & 48 & 21 \\
\hline 03 & 0 & 0 & 0 & 0 & 0 & 0 \\
\hline 04 & 0 & 0 & 25 & 0 & 0 & 0 \\
\hline 05 & $N$ & 42 & $N$ & 32 & $N$ & 0 \\
\hline 06 & $N$ & 32 & $N$ & 0 & $N$ & 0 \\
\hline 07 & $N$ & 38 & $N$ & 27 & $N$ & 16 \\
\hline 08 & $N$ & 0 & $N$ & 0 & $N$ & 0 \\
\hline $\begin{array}{l}\text { Negative } \\
\text { control }\end{array}$ & 0 & 0 & 0 & 0 & 0 & 0 \\
\hline $\begin{array}{l}\text { Positive } \\
\text { control }\end{array}$ & $23-25$ & $23-30$ & $21-24$ & $21-22$ & $17-22$ & $17-21$ \\
\hline
\end{tabular}

\section{Information gathered from poultry farm owners}

All farms perform a complete cleaning process once in 30 - 45 days after one whole batch of animals are sent to slaughter and before purchasing a new batch of chicks. First, Bramble which is applied on the floor is removed completely and the cages are cleaned using a disinfectant and left for 2 - 3 days. Next, slaked lime is applied on the floor and kept for 10-15 days for total decontamination. The outside environment of the cages and containers which are used for serve feed and water are thoroughly cleaned.

All selected farms have not reported any disease for past three months at the time of the visit. All farm owners claim that the farms are visited regularly by a public health inspector. When animals get ill they seek the advice from a veterinary surgeon and in the case when an animal is found dead, they are buried without selling for meat. Chicken stool collected in the farms is sold or being used as a fertilizer.

In most of the farms (15/18) all activities in the farm are carried out by the farm owner and his/ her family members and only in 3 farms there were two extra workers in each. Safety precautions such as wearing gloves and masks are followed by workers only in 11 farms (61\%). Forty-four percent of farm owners $(08 / 18)$ believe that routine use of antibiotics in poultry is not a good practice and harmful for human health. Similar percentage of farm owners' $(44 \%)$ declared that routine use of antibiotics in poultry is a favourable practice as it benefits them economically. None of the farm owners who responded (16/16) were aware on the effects of using antibiotics in poultry on increasing antibiotic resistance in the community.

\section{Discussion}

Food samples collected from shops in Kegalle district as well as ready to serve food samples collected from farms in Kegalle district did not show any antibacterial action against Staphylococcus aureus ATCC25923, Escherichia coli ATCC25922 and Pseudomonas aeruginosa ATCC27853. This verifies that poultry feed itself may not contain any antibiotic substances and such additives are 
not being added to food before it is served to animals at the poultry farms.

But water samples collected from $33 \%$ of farms has demonstrated antibacterial effect against one or more of the above standard organisms, emphasizing that antibiotics are given to animals along with served drinking water. This study has identified eight additives being incorporated into drinking water of poultry out of which $62.5 \%$ containing antibiotics. The antibiotic activity of the concentration of some additives used in the served water samples in some farms are higher than that the positive control indicating a significantly higher antibiotic concentrations are being fed to poultry.

A study done by the Johns Hopkins University Bloomberg School of Public Health demonstrate the presence of residues of 2-10 antibiotics and 7 other medications in feather meal samples; a type poultry feed made out from feathers of killed poultry. They also showed that these residual concentrations are high enough to select the resistant bacterial strains when tested against $E$. coli. (8)

It is found that high antibiotic residues were present in $40 \%$ of samples taken from commercially manufactured poultry feed in the Delhi-National Capital Region of which $17 \%$ had multiple antibiotics (2).

Although the WHO has prohibited the application of antibiotics as growth promoters in food animal production sector, Sri Lanka still allows the use of antibiotics; avoparcin, carbadox, and flavophospholipol as growth promoters in poultry sector (9). In routine practice, different commercial products; with different trade names are used in poultry farms as growth promoters. Not only in Sri Lanka but also in India, antibiotics are being used as growth promoters across the country highlighting India as one of the global hotspots for antibacterial resistance (13).

The poultry farms in Kegalle District use several antibiotics namely enrofloxacin by 3 farms, sulfamethazine by 3 farms, trimethoprim by 3 farms, tylosin by 2 farms, neomycin by 4 farms and oxytetracycline by 4 farms with the aim of preventing and treating several bacterial infections. Most of them are used in farms daily or once in a week or monthly. In North America, antibiotics such as tetracycline, bacitracin, tylosin, salinomycin, virginiamycin and bambermycin are widely used. Also in the United States, tetracyclines are the most commonly used drug which exceeds two-thirds of the total amount of drugs given to animals (14).

The WHO's list of critically important antibiotics for human health includes ampicillin, amoxicillin, cefadroxil, chlortetracycline, doxycycline, erythromycin, flumequine, gentamicin, veneomycin, oxytetracycline, spiramycin, sulfadiazine and sulfadimethoxine which are restricted to use in the veterinary sector (13). But still, Oxytetracycline is used in 4 farms out of 18 farms (22.2\%) in Kegalle district. In contrast, in India 11 such antibiotics were found in the chicken feed (2).

Proper guidelines regarding the types of antibiotics and their minimum and maximum amounts to be used for treating several diseases have not yet been formulated in Sri Lanka. Therefore, several drugs are used for treatment and prophylaxis in farms without considering any limitation due to unrestricted sale and over the counter availability of antibiotics in Sri Lanka. Left over water fed to animals containing antimicrobial residues can contaminate the environment via poultry stools, soil and ground water. This factor may also contribute for the emergence of antibiotic resistant strains in the community.

\section{Conclusions and recommendations}

Commercially available poultry feeds in shops and ready to serve in poultry feeds in farms in Kegalle District did not demonstrate any antibacterial activity. But drinking water served to animals in poultry farms in Kegalle District exhibit antibacterial activity due to incorporation of antibiotics containing additives. Antibiotics are used in the poultry sector as growth promoters and for prophylaxis and treatment of infections beyond the prevailing national and international standards. A significant percentage of farm owners claim that usage of antibiotics in poultry is a favourable practice as it benefits them economically. The awareness of farm owners on the contribution antibiotic use in poultry to the development of antibiotic resistance in the community is not satisfactory. 
National guidelines should be developed to regulate the use of antibiotics as growth promoters declaring the types of antibiotics with their specific concentrations and the maximum residue limits for antimicrobials in poultry products. The prophylactic and sub-therapeutic use of antibiotics in poultry should be banned. A surveillance system should be implemented to monitor these practices as well as to monitor the antibiotic resistance pattern in livestock. Poultry farmers as well as consumers should be educated on the dangers of antibiotic resistance.

\section{Limitations}

Some poultry farm owners did not declare all the types of additives they used. Acts, regulations and guidelines regarding the usage of antibiotics in the poultry sector in Sri Lanka were very difficult to find as those data were not freely available.

\section{References}

1. Agyare C, Boamah VE, Zumbi CNZ and Osei FB. Antibiotic Use in Poultry Production and Its Effects on Bacterial Resistance - Chapter 3, Antimicrobial Resistance -A Global Threat 2019. DOI: 10.5772/intechopen. 79371.

2. Center for Disease Economics \& Policy 2016. Antibiotic Use and Resistance in Food Animals; Current Policy and Recommendations, Global Antibiotic Resistance Partnership. Washington USA.

3. US Food and Drug Administration - Center for Veterinary Medicine - 2019. Summary Report on Antimicrobials Sold or Distributed for Use in Food-Producing Animals; FDA 2020.

4. Jayalakshmi K, Paramasivam M, Sasikala M, Tamilam TV and Sumithra A. Review on antibiotic residues in animal products and its impact on environments and human health. Journal of Entomology and Zoology Studies. 2017; 5(3): 1446-1451.

5. Van Boeckel TP, Brower C, Gilbert M, et al. Global trends in antimicrobial use in food animals. Proceedings of the National Academy of Sciences. 2015; 112(18): 5649-5654.
6. Herath EM, Palansooriya AGKN, Dandeniya WS and Jinadasa RN. An assessment of antibiotic-resistant bacteria in poultry litter and agricultural soils in Kandy district, Sri Lanka. Tropical Agricultural Research. 2016; 27(4): 389-398.

7. WHO guidelines on use of medically important antimicrobials in food-producing animals, World Health Organization 2017. Available from: https://apps.who.int/iris/bitstream/handle/10665/258970/ 9789241550130-eng.pdf? sequence $=1 \% 0 \mathrm{~A}$.

8. John Hopkins University Bloomberg School of Public Health. Researchers find evidence of banned antibiotics in poultry products - Analysis of feather meal suggests continued use of fluoroquinolone antibiotics despite 2005 FDA ban. Public release: 5 April 2012. Available from: https://www.eurekalert.org/pub_releases/2012-04/jhubrfe040512.php

9. Animal Feed Act No. 15 of 1986 . The Democratic Socialist Republic of Sri Lanka.

10. National Strategic Plan for Combating Antimicrobial Resistance in Sri Lanka, 2017-2022. Ministry of Health 2017. ISBN 978-955-0505-95-1.

11. Lemeshow S, Hosmer DW (Jr), Klar J, Lwanga SK. Adequacy of sample size in health studies, World Health Organization 1990. John Wiley \& Sons Ltd. (ISBN 0471 925179).

12. Karunarathna RMCS and Wijayaratne GB. Extended spectrum beta lactamase producing Escherichia coli prevalence of chicken stools in selected broiler farms in Galle District. $1^{\text {st }}$ Research Symposium of the Faculty of Allied Health Sciences (RuFAS), $8^{\text {th }}$ November 2018. Proceedings of RuFAS 2018; 7.

13. Sivaraman S. Antibiotic Use in Food Animals: India Overview, Re Act Asia-Pacific 2018. Available from: https://www.reactgroup.org/wp-content/uploads /2018/11/Antibiotic_Use_in_Food_Animals_India_ LIGHT_2018_we b.pdf.

14. Mehdi Y, Létourneau-Montminy MP, Gaucher ML, et al. Use of antibiotics in broiler production: Global impacts and alternatives. Animal Nutrition. 2018; 4(2):170-178. DOI: https://doi.org/10.1016/j.aninu.2018.03.002 